\title{
Factors that Influence Professional Socialization in Nursing Students A Multigroup Analysis
}

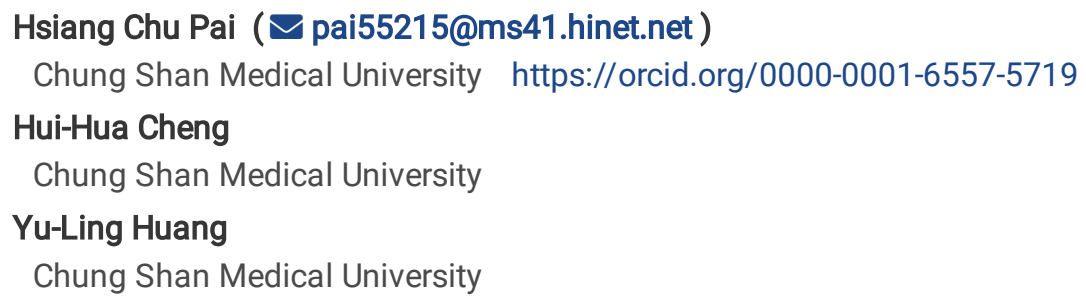

\section{Research article}

Keywords: Caring, Nursing Student, Nursing Competence, Self-Reflection, Professional Socialization

Posted Date: July 7th, 2020

DOI: https://doi.org/10.21203/rs.3.rs-40393/v1

License: 다 (i) This work is licensed under a Creative Commons Attribution 4.0 International License. Read Full License 


\section{Abstract \\ Background}

Nursing professional socialization significantly influences the sustainable development of nursing students' careers. Nevertheless, there is still a lack of research on the factors that influence nursing professional socialization in nursing education. This study aims to examine the factors that influence professional socialization in nursing students. The study adopts a multigroup approach for comparison between female and male subsamples.

\section{Methods}

This is a cross-sectional, quantitative study of a sample of 108 nursing students ( 80 females and 28 males). The Simulation Learning Effectiveness Scale, Caring Assessment Report Evaluation Q-sort, Self-Reflection and Insight Scale, and Holistic Nursing Competence Scale were used to collect the data on the independent variables. The Team Skills Scale, Nursing Image as a Profession questionnaire, and Nursing Professional Commitment Scale were used to assess the level of students' nursing professional socialization, which is an outcome construct variable. A multigroup analysis with partial least squares structural equation modeling was used to analyze the data and to examine the professional socialization research model.

\section{Results}

The full model findings show that individual learning effectiveness had a significantly positive effect on nursing students' caring behavior ( $(B=0.47, p<.001)$ and on self-reflection and insight $(B=0.32, p<0.1)$. In addition, caring behavior $(B=0.64, p<.001)$ and self-reflection and insight $(B=0.29, p<.001)$ had a significantly positive effect on nursing competence. Finally, nursing competence also had a significantly positive effect on nursing professional socialization $(B=0.61, p<.001)$. Overall, all independent variables were significant predictors of nursing professional socialization, explaining $36.7 \%$ of the variance in the integrated model of professional socialization. In addition, a permutation test revealed no differences in the two comparisons' path coefficient estimates in the model (female vs. male).

\section{Conclusion}

The findings reveal that the result of an all-path coefficient parametric on the professional socialization model does not differ by gender. Therefore, for both female and male students, it is important to further strengthen nursing students' self-learning effectiveness to promote their self-reflection and caring behavior. Increasing students' nursing competence is a key factor in improving their professional socialization.

\section{Background}

Professional socialization, a process to acquire specialized knowledge, skills, attitudes, values, norms, and interests within nursing [1], has received attention in recent years. Such socialization is vital for the realization of nurses' professional roles and for the process of professional self-growth, and the student assumes a more professional role as knowledge and socialization are acquired in nursing school.

It is important to understand the development of a professional identity and its impact factors. Research indicates that professional identity is developed through interaction with peers and internalization of knowledge, skills, norms, values, and culture when students are in a nursing program [2]. Effective professional socialization provides sustainable development of student learning and professionalism, and it is important to pay attention to the integration of professional socialization into nursing education early in the learning process [3].

Research shows that the impact that nursing education has on professional socialization depends on the students' engaging in a reflective learning process and on the beliefs and values promoted in the course [4]. A systematic literature review indicates that many studies on the antecedents of nursing professional socialization focus on setting, profession, and role model [5]. There is, however, a

Page 2/16 
lack of research on students' individual learner factors that influence professional socialization in nursing education. Therefore, this study aims to explore the factors that influence students' professional socialization as a means for the design of nursing programs to be strengthened. The objectives of this study are as follows: (1) To verify the reliability and validity of the professional socialization model as a means to study the key aspects of self-learning effectiveness, caring behavior, self-reflection, and nursing competence. (2) To determine whether there are differences in the effects of the professional socialization model in terms of gender. In order to achieve the above research purposes, we perform the following literature review.

\section{The Relationships Between Simulation Self-Learning Effectiveness, Self-Reflection and Insight, and Caring Behavior}

Early in their training, nursing students complete basic nursing courses at school and then serve in a clinical hospital internship. The clinical environment is best suited to learning skills and for professional socialization [6-7]. In recent years, however, in consideration of patient safety, schools have added simulation clinical skills centers, and novice nursing students continue to learn and practice in the school clinical skills center. Although the technical aspects of the profession are important, caring and self-reflection also need to be cultivated, and the student's learning effectiveness in the overall clinical context is important.

Bandura defined perceived self-efficacy as individuals' judgment of their capabilities [8]. It is concerned not with skills, per se, but with judgments of whatever skills one possesses. Self-efficacy plays a role in promoting individuals' efforts to engage in behaviors. A study of nursing students found that there is a positive relationship between simulation learning effectiveness and self-reflection; that is, the higher the learning effectiveness, the higher the students' self-reflection and insight [9]. Caring behavior is considered to be the core of nursing [10]. One study found that self-efficacy is a predictor of caring behavior [11]. In addition, Chen et al. found that students present greater caring behavior when they also present with higher self-reflection and insight [12].

\section{The Relationships Between Self-Reflection, Caring Behavior, and Nursing Competence}

Watson defined competency as the skills that a nurse possesses upon completion of an educational program [1]. According to McCloskey, "Competency is an ability, talent, or skill that allows someone to do something" (p. 356) [13]. Nursing competency has always been an important task for nursing schools to cultivate in their students. In the process of ability cultivation, especially in clinical situational learning, students face cases in which patients have different care needs and changes in their condition. This means that, in addition to being able to provide appropriate care, the students must be self-reflective and have insight.

Previous research has found that self-reflection is significantly positively associated with students' nursing competence [9, 14]. Pai's study also indicated that a clinical practice program with self-reflection learning exercises enhance students' clinical competence [15]. In addition, Naidu found that caring behavior affects patient satisfaction and healthcare quality [16]. These findings show that students' self-reflection and caring behavior are correlated with their nursing competence.

\section{Professional Socialized and Nursing Competence}

Socialization is the process of learning a group's new role, knowledge, and skills in the context of society. It is the acquisition of behavior and attitudes that allow individuals to become members of groups and society. Professional socialization refers to one process of professional learning, including the learning of professional norms, attitudes, behaviors, skills, roles, and interests [1]. The individual must internalize the values and norms of the profession in terms of his or her behavior and self-concept, and professional socialization is needed for learning [7].

Arnold et al. found that teamwork can promote individual professional socialization [17]. In keeping with this, Watson believes that individual professional image and professional commitment are part of professional socialization [1]. Research shows that professional socialization can promote better professional role behavior for novice caregivers [18]. Dinmohammadi et al. conducted a concept analysis of nursing professional socialization and found that professional socialization is a complex process with four key attributes: learning, interaction, development, and adaptation [5]. Salisu et al. stated that the attributes and antecedents of professional identity of the nurse are related to the personal dimensions of competence, confidence, insight, capability, and selfreflection ability [2]. Nursing competency also has an influence on professional socialization $[1,5,6,18]$.

\section{Framework and Hypotheses}

We extend the extant literature by focusing on professional socialization. In this study, simulation self-learning effectiveness, selfreflection with insight, caring behavior, and nursing competence are considered antecedents (exogenous constructs), and professional 
socialization is an outcome variable (endogenous construct). In this study, simulation self-learning effectiveness is defined as students' perceived efficacy, such as self-regulation, self-efficacy, and self-motivation, when they perform simulation practice in a school clinical skill center [19]. Caring behavior is defined as intentional actions that convey physical care and emotional concern and promote a sense of security in another [20]. Self-reflection and insight is defined as an inspection, evaluation, and understanding of one's thoughts, feelings and behaviors [21]. Nursing competence is defined as "the ability of a nurse to effectively demonstrate a set of attributes, such as personal characteristics, professional attitude, value, knowledge, and skill, and to full his/her professional responsibility through their practice [22]. In addition, professional socialization is diverse and has a wide scope. Based on a review of the literature, we drew upon the concept of teamwork in which students practice in groups. Thus, in this study, we define professional socialization as encompassing an attitude that includes nursing image, professional commitment, and teamwork skills. The research model is shown in Figure 1, and the hypotheses are as follows:

H1a: Students' self-learning effectiveness has a significant positive association with caring behavior.

H1b: Students' self-learning effectiveness has a significant positive association with self-reflection and insight.

H1c: Students' scaring behavior has a significant positive association with self-reflection and insight.

H2a: Students' caring behavior has a significant positive association with nursing competence.

H2b: Students' self-reflection with insight has a significant positive association with nursing competence.

H3: Students' nursing competence has a significant positive association with nursing professional socialization.

\section{Methods}

\section{Research Design and Participants}

This study used a cross-sectional, quantitative design. Participants $(N=108)$ were recruited from a university in Central Taiwan. Inclusion criteria were students who: (1) participated in a fundamental nursing laboratory course, and (2) have performed clinical simulation care practice. Their ages ranged from 20 to 24 years $(M=20.48 ; S D=0.68)$. Of the 108 nursing students, $80(74.1 \%)$ were female, and 28 (25.9\%) were male.

\section{Procedure}

Students who met the inclusion criteria and were willing to participate in this study were informed of the purpose of the research and that they had the right to refuse to answer any questions or to withdraw from the study. The researchers also explained that, if they did not participate the study, it would not affect their curriculum performance. Participants were invited to sign a consent form after receiving a brief overview of the study's objectives. To thank participants for completing the questionnaire and providing information, the researchers provided an NT\$100 gift certificate to each participant. Data were collected in October 2018. All students' questionnaires were anonymous.

\section{Measures}

We invited three experts who were familiar with nursing education and practice to examine all of the scales. The content validity index of all scales was above 0.86 , in keeping with the recommendation to be at least 0.80 [23]. The scales had a Cronbach's alpha range of $0.73-0.95$, which meets the threshold of 0.70 [24]. The scales are as follows:

\section{Simulation Learning Effectiveness Scale (SLES)}

The SLES, developed by Pai [19], is based on social cognitive theory and includes the three subscales of self-motivation, selfregulation, and self-efficacy. There is a total of 12 items, with each item's using a 5-point Likert scale, ranging from $1=$ strongly disagree to $5=$ strongly agree, with a higher score as corresponding to greater learning effectiveness.

Caring Assessment Report Evaluation Q-sort (CAREQ) 
The CAREQ, which comprises 40 items, is based on the work of Chen et al. [25]. The three subscales of the CAREQ scale are sense of security, comfort, and accessibility. The items are rated on 5-point Likert scale, ranging from $1=$ strongly disagree to $5=$ strongly agree, with higher scores as corresponding to greater caring behaviors.

\section{Self-Reflection and Insight Scale (SRI-S)}

The 20-item SRI-S, based on the work of Chen et al. [26], was adapted from the original to be appropriate for nursing students [21]. The three subscales of SRI-S are engage in self-reflection, need for self-reflection, and insight. The items are rated on 5-point Likert scale, ranging from $1=$ strongly disagree to $5=$ strongly agree, with higher scores as corresponding to greater levels of self-reflection and insight $[21,26]$.

\section{Holistic Nursing Competence Scale (HNCS)}

The HNCS, comprising 27 items, is based on the work of Takase and Teraoka (2011) [22]. The four subscales of the HNCS are general aptitude, ethically oriented practice, nursing care in a team, and professional development. The items are rated on 7-point Likert scale, ranging from $1=$ not at all [competent] to 7 = always [competent], with higher scores as corresponding to greater nursing care competence.

\section{Professional Socialization Scale (PSS)}

In the PSS, three subscales are used to examine student nurses' professional socialization in terms of attitude: Nursing Image as a Profession Questionnaire (NIPQ), Professional Commitment Scale (PCS), and Teamwork Skills Scale (TSS). There are 22 items on the NIPQ [27, 28], 34 items on the PCS [29], and 17 items on the TSS [30]. The items are rated on a 5-point Likert scale, ranging from $1=$ strongly disagree (or poor) to $5=$ strongly agree (or excellent), with higher scores as corresponding to greater nursing professional socialization in regard to attitude.

\section{Data Analysis}

As recommended by Cain et al. and Hair et al. [31-32], we examined the multivariate skewness and kurtosis of the data through certain software tools (https://webpower.psychstat.org/wiki/tools/index). The results indicated that Mardia's multivariate skewness ( $\beta=$ $78.98, p<.001)$ and Mardia's multivariate kurtosis $(\beta=334.69, p<.001)$ were not present in the multivariate normal data distribution [31]. Therefore, we used the SmartPLS (version 3.2.8) software [33], a non-parametric analysis that uses partial least squares to analyze the research model; it is also used when the sample size is small [32].

In this study, latent variables (constructs) included self-learning effectiveness, caring behavior, self-reflection with insight, nursing competence, and nursing professional socialization. Each latent variable is assessed by two to four measured/observed variables. First, we conducted the permutation algorithm to examine whether the indicators associated with each construct are invariant between females and males. Then, we conducted the measurement invariance of composite models (MICOM) procedure to test measurement model invariance, also referred to as measurement equivalence [34]. The MICOM procedure involves three steps-examination of (1) configural invariance, (2) compositional invariance, and (3) equality of composite mean values and variance. Next, we used multigroup analysis (MGA; permutation algorithm) via the SmartPLS tool with partial least squares structure equation modeling (PLSSEM) to compare the two groups (female and male) and to test whether pre-defined data groups have statistically significant differences in gender-group parameter estimates. Finally, PLS-SEM was used to test the overall model.

\section{Human Subjects Considerations}

The executed procedure of this study was approved by the Ethics Board of Chun Shan Medical University Hospital, Taiwan (CSMUH No: CS2-18026).

\section{Results}

\section{Reliability and Validity of the Measure Model}

Reliability and convergent validity are usually ascertained by examining the composite reliability, factor loading, and average variance (AVE) $[32,35]$. As shown in Table 1, the composite reliability of all constructs was higher than 0.85 , which exceeds 0.6 , the threshold of 
acceptability [32]. The loadings of indicators were all greater than 0.73 , which exceeds 0.70 , the threshold for acceptability [32]. Further, the average variance extracted (AVE) of all constructs were higher than 0.65 , which exceeds 0.5 , the threshold for convergent validity [35].

[Insert Table 1 about here]

In addition, as shown in Table 2, in terms of discriminant validity, the square root of the AVE of all latent constructs is higher than its correlations with any other latent variable. Thus, according to the Fornell-Larcker criterion [36], discriminant validity is achieved. In summary, for both the total sample and each subsample (female and male) the PLS analysis shows that the reliability and validity of the measurement models are satisfactory.

Next, a permutation algorithm was used to determine whether the indicators associated with each construct are invariant between females and males. As the results in Table 3 show, the difference between the factor loadings of both groups are all nonsignificant $(p$ $>$.05).

[Insert Table 2 and Table 3 about here\}

In addition, we conducted MICOM Step 1 to examine whether significant intergroup (female and male) differences are due to intergroup differences in constructs. As shown in Table 4, the MICOM test indicated that comparing the correlation $c$ between the composite score of the female and male group with the $5 \%$ quantile indicated that the quantile is smaller than (or equal to) the correlation $c$ for all of the constructs. The $p$-values are higher than 0.05 , indicating that configural invariance has been established for these constructs.

[Insert Table 4 about here]

Similarly, Step 2 was conducted to assess whether the composite scores differ significantly between females and males. The MICOM procedure revealed that the composite scores are not significantly different, indicating that compositional invariance has been established. These two steps support measurement invariance and indicate that partial measurement invariance is established. Step 3 was conducted to examine whether there are equal mean variances between females and males on the composite scores. The results reveal that there are no significant differences in the mean values and variances of construct between the two groups. In summary, full measurement invariance is confirmed, supporting the pooled data analysis [34].

\section{Structure Model tests}

\section{Permutation Test}

Table 5 present the results of the path coefficient parametric and permutation tests on the MGA, including for females, males, and the full model. Except for one, all approaches result in similar findings; the exception is that self-effectiveness does not have a significant impact on self-reflection for males $(B=.22, t=1.22, p>.05)$. Finally, the permutation test was used to identify whether gender group has an influence on the overall professional socialization model. The findings reveal that all of these variables confirm that the causal effect between exogenous and endogenous constructs are not influenced by gender.

[Insert Table 5 about here]

\section{Testing the Model Fit Hypotheses Results With the Total Sample}

Henseler et al. state that model fit includes an assessment of standardized root mean square residual $(\mathrm{SRMR}<0.08)$ [35]. In this study, the SRMR value of the saturated model was 0.07 , showing an acceptable fit of the data to the model.

As shown in Figure 1 and Table 5, self-learning effectiveness positively influenced caring behavior $(B=0.47, t=5.727, p<.001)$ and self-reflection with insight $(\beta=0.32, t=3.318, p<.01)$ explaining $22 \%\left(Q^{2}=0.182\right)$ of the variance in caring behavior and $20.2 \%\left(Q^{2}=\right.$ 0.127) of the variance in self-reflection. Although caring behavior positively influenced self-reflection with insight $(\beta=0.21)$, the finding was insignificant $(t=1.748, p>.05)$. The findings support $\mathrm{H} 1 \mathrm{a}$ and $\mathrm{H} 1 \mathrm{~b}$, whereas $\mathrm{H} 1 \mathrm{c}$ is not supported. In addition, caring behavior $(\beta$ $=0.64, t=9.891, p<.001)$ and self-reflection with insight $(B=0.29, t=3.543, p<.001)$ positively influenced nursing competence, explaining $62.1 \%\left(Q^{2}=0.455\right)$ of the variance in nursing competence. This provides support for $\mathrm{H} 2 \mathrm{a}$ and $\mathrm{H} 2 \mathrm{~b}$. 
Next, we looked at the predictive effects on professional socialization. Nursing competence $(B=0.61, t=8.968, p<.001)$ was a significant predictor of professional socialization, explaining $36.7 \%\left(Q^{2}=0.213\right.$; effect size $\left.f^{2}=0.58\right)$ of the variance in professional socialization. This provides support for $\mathrm{H} 3$.

[Insert Figure 1 about here]

\section{Discussion}

The results confirm the composite reliability, convergent validity, and discriminant validity (Fornell-Larcker criterion) of the measurement model (Tables 1 and 2) for both the full sample and for the two gender subsamples. In addition, the measurement invariance was confirmed. In the other words, the measurement model does not change when the full simple is divided into two samples (female and male; Tables 3 and 4), supporting the pooled data analysis [34].

Thus, we examined the path coefficient parametric and permutation tests in the MGA, including for females, males, and the full sample (Table 5). The results indicated that, with one exception, i.e., self-effectiveness does not have significant impact on selfreflection for the male group, the approaches present similar findings for the entire sample, female group, and male group. This may be due to a smaller number of males. The permutation test, however, reveals that all path coefficients have equal variances between the female and male groups. In other words, all of the variables that have a causal effect between exogenous and endogenous constructs do not have an influence by gender [34].

Finally, we examine the research model and all hypotheses. For the full model, the findings support moderate power $\left(R^{2}\right)$ and high predictive validity $\left(\mathrm{Q}^{2}\right)$ of the professional socialization model as a framework. As can be seen in Figure 1 , for nursing competence, $R^{2}$ $=62.1 \%$, and for professional socialization, $R^{2}=36.7 \%$ (effect size $\mathrm{f}^{2}=0.58$ ). Hair et al. recommends that, in general, $R^{2}$ values of $0.75,0.50$, and 0.25 for endogenous constructs can be described, respectively, as substantial, moderate, and weak [32]. Thus, in this study, there was nearly a moderate $R^{2}$ value in the path model. Moreover, the endogenous variables' resulting $\mathrm{Q}^{2}$ values were larger than 0 , which indicates that exogenous constructs have predictive relevance for the endogenous construct [32].

The findings for the full model suggest that perceived self-learning effectiveness has a significant impact on caring behavior and selfreflection. This supports previous studies that found that students who have higher learning learning effectiveness present greater self-reflection and insight ability [9]. The results also confirm Bandura's contention that self-efficacy plays a role in promoting individuals' efforts, particularly in terms of positive behavior [8]. An earlier study, however, found that students who have greater caring behavior report higher self-reflection and insight [12]. The current study shows that the path between caring behavior and selfreflection does not have a significant impact. The inconsistency is in keeping with previous studies that have not included self-learning performance factors in their research models [12]. In our study, we added the self-learning effectiveness factor, which enables selflearning effectiveness to have more of an impact on self-reflection and makes the influence of caring behavior on self-reflection weak. This may mean that self-learning effectiveness contributes more to the impact of self-reflection and insight than does caring behavior.

The findings also show that caring behavior and self-reflection have a significant impact on nursing competence. In other words, students who have more caring behaviors and self-reflection present greater nursing competence. These findings are consistent with those of earlier studies that found that caring behavior was significantly positively associated with students' nursing competence [9, 14]. This finding also echoes previous literature that has identified caring behavior as an important core competency of nursing [10, 37]. In addition, the findings indicated that students who have more self-reflection present greater nursing competence, which also supports the work of Pai [15], who found that a clinical practice program with self-reflection learning exercises enhances students' clinical competence.

Finally, the findings show that nursing competence has a significant impact on professional socialization in regard to attitude. Students who have greater nursing competence present greater professional socialization. This finding also is in keeping with the importance of nurturing nursing capacity in promoting professional socialization $[1,5,6,18]$.

\section{Limitationsand Future Directions}

There are several limitations that should be noted. First, this study used a cross-sectional design, which limits the generalizability of the findings. Thus, it is recommended that future research use a longitudinal study design to provide more conclusive evidence of linear relationships. Second, our participants were drawn from a convenience sample. We thus recommend that future research should 
sample participants from different geographic regions or cross-culturally, which should help to strengthen this research model. Nevertheless, in the present study, we used robust statistic procedures to determine the validity of the relationships among variables. Our findings can be used as the basis for the construction of future models of professional socialization. Third, the participants are second-year university students (junior students) who are participating in the practice of nursing skills for the first time. Due to this limitation, the research results can be used only to understand the initial performance of the students' professional socialization in regard to attitude. If researchers continue to track their professional socialization performance, we will have a better understanding of the trajectory of professional socialization. Finally, this study's framework is based on the literature review, which shows a relationship between self-learning effectiveness, caring behavior, self-reflection, nursing competence, and professional socialization in regard to attitude. Some factors, such as personal characteristics or the learning/job environment, were not included in the present model. We recommend that future study explore the contribution of additional factors to a professional socialization model. Finally, this study's framework is based on the literature review, which shows a relationships between self-learning effectiveness, caring behavior, selfreflection, nursing competence, and professional socialization. Some factors, such as personal characteristics or the learning/job environment, were not included in the present model. Thus, we recommend that future study explore the contribution of additional factors to a professional socialization model.

\section{Conclusion And Relevance To Clinical Practice}

We determined that the variables related to the causal effect between exogenous and endogenous constructs are not different by gender groups. Therefore, we tested the research model for the entire sample. The starting point of our research model is self-learning effectiveness, which directly and positively affects students' self-reflection and caring ability, providing a further positive impact on students' nursing competence performance. In particular, the impact of caring behavior on nursing competence is higher than that of self-reflection on nursing competence. The results of this chain effect show the effect of self-learning effectiveness on learning ability [8]. Moreover, we validated that the latent variable of professional socialization comprises the three indicators of teamwork skills, professional commitment, and professional image. Further, we found that the explanatory power of nursing ability for professional socialization is $36.7 \%$. In sum, we find that, for the construct of nursing professional socialization, the starting point is self-learning effectiveness, followed by nursing ability, which also promotes professional socialization. For school nursing education to promote students' professional socialization, it is important to design a program to improve students' learning effectiveness, which could then enhance students' self-reflection and caring behavior as well as their nursing competence.

\section{Abbreviations}

SLES: Simulation Learning Effectiveness Scale; CAREQ: Caring Assessment Report Evaluation Q-sort; SRI-S: Self-Reflection and Insight Scale; HNCS: Holistic Nursing Competence Scale; PSS: Professional Socialization Scale; NIPQ: Nursing Image as a Profession Questionnaire; PCS: Professional Commitment Scale; TSS: Teamwork Skills Scale; MICOM: Measurement invariance of composite models; MGA: Multigroup analysis; PLS-SEM: Partial least squares structure equation modeling; AVE: Average variance extracted; SRMR: Standardized root mean square residual.

\section{Declarations}

\section{Ethics approval and consent to participate}

The executed procedure of this study was approved by the Ethics Board of Chun Shan Medical University Hospital, Taiwan (CSMUH No: CS2-18026).

\section{Consent to publish}

Not applicable

\section{Availability of data and materials}

The datasets used and/or analyzed during the current study are available from the corresponding author on request.

\section{Competing interests}


The authors declare no conflicts of interest.

\section{Funding}

The Ministry of Education for funding this study.

\section{Authors' Contributions}

HCP was responsible for the study conception and design, and in drafting of the manuscript, made critical revisions to the paper for important intellectual content. HHC and YLH performed the data collection. HCP performed the data analysis and supervised the study.

\section{Acknowledgments}

We wish to thank Professor Sally Blomstrom, Wen-Jiuan Yen, Kuei-Yun Lu, and Miyuki Takase, who provided the scales for this study.

\section{References}

1. Watson AB. Professional socialization of the registered nurse. In: Holzemer W, editor. Review of research in nursing education. Vol. 1. New York: National League for Nursing; 1986. pp. 41-71.

2. Salisu WJ, Dehghan Nayeri N, Yakubu I, Ebrahimpour F. Challenges and facilitators of professional socialization: A systematic review. Nurs Open. 2019;6(4):1289-98.

3. Kerin Ú. Professional socialisation processes help facilitate the transition from student to qualified nurse. Evid Based Nurs. 2020;23(2):47.

4. Howkins EJ, Ewens A. How students experience professional socialisation. Int J Nurs Stud. 1999;36(1):41-9.

5. Dinmohammadi M, Peyrovi H, Mehrdad N. Concept analysis of professional socialization in nursing. Nurs Forum. 2013;48(1):2634.

6. Kim S, Shin YS. Structural model of professional socialization of nursing students with clinical practice experience. J Nurs Educ. 2020;59(3):133-41.

7. Lai PK, Pek H. Concept of professional socialization in nursing. International e-Journal of Science Medicine Education. 2012;6(1):5-31.

8. Bandura A. Social foundations of thought and action: A social cognitive theory. Englewood Cliffs: Prentice-Hall; 1986.

9. Pai H-C, Ko HL, Eng C-J, Yen W-J. The mediating effect of self-reflection and learning effectiveness on clinical nursing performance in nursing students: A follow-up study. J Prof Nurs. 2017;33(4):287-92.

10. Zamanzadeh V, Valizadeh L, Azimzadeh R, Aminaie N, Yousefzadeh S. First and fourth-year students' perceptions about the importance of nursing care behaviors: Socialization toward caring. J Caring Sci. 2014;3(2):93-101.

11. Allari RS, Atout $M$, Hasan AA. The value of caring behavior and its impact on students' self-efficacy: Perceptions of undergraduate nursing students. Nurs Forum. 2020;(Early view online version):1-8.

12. Chen SY, Chang HC, Pai HC. Caring behaviours directly and indirectly affect nursing students' critical thinking. Scand J Caring Sci. 2018;32(1):197-203.

13. McCloskey JC. The effects of nursing education on job effectiveness: An overview of the literature. Res Nurs Health. 1981;4(4):355-73.

14. Eng C-J, Pai H-C. Determinants of nursing competence of nursing students in Taiwan: The role of self-reflection and insight. Nurse Educ Today. 2015;35(3):450-55.

15. Pai H-C. The effect of a self-reflection and insight program on the nursing competence of nursing students: A longitudinal study. $J$ Prof Nurs. 2015;31(5):424-31.

16. Naidu A. Factors affecting patient satisfaction and healthcare quality. Int J Health Care Qual Assur. 2009;22(4):366-81.

17. Arnold C, Berger S, Gronewold N, Schwabe D, Gotsch B, Mahler C, Schultz JH. Exploring early interprofessional socialization: A pilot study of students' experiences in medical history taking. J Interprof Care. 2020; Early view online version: 1-8. 
18. Ke YT, Kuo CC, Hung CH. The effects of a nursing preceptorship on new nurses' competence, professional socialization, job satisfaction and retention: A systematic review. J Adv Nurs. 2017;73(10):2296-305.

19. Pai H-C. Development and validation of the Simulation Learning Effectiveness Scale for nursing students. J Clin Nurs. 2016;25(21-22):3373-81.

20. Larson PJ, Ferketich SL, Wleczorek RR, Molzahn AE. Patients' satisfaction with nurses' caring during hospitalization. West J Nurs Res. 1993;15(6):690-707.

21. Grant AM, Franklin J, Langford P. The self-reflection and insight scale: A new measure of private self-consciousness. Soc Behav Pers. 2002;30(8):821-36.

22. Takase M, Teraoka S. Development of the holistic nursing competence scale. Nurs Health Sci. 2011;13(4):396-403.

23. Yaghmaie F. Content validity and its estimation. J Med Educ. 2003;3(1):25-7.

24. Cronbach LJ. Coefficient alpha and the internal structure of tests. Psychometrika. 1951;16:297-334.

25. Chen SY, Yen WJ, Lin YJ, Lee CH, Lu YC. A Chinese version of the Caring Assessment Report Evaluation Q-sort scale for measuring patients' perception on nurses' caring behaviours: Reliability and validity assessment. I Int J Nurs Pract. 2012;18(4):388-95.

26. Chen SY, Pai HC, Hsu HC. Factor construct of self-reflection and insight scale of Taiwanese student nurses. Paper presented at NET2013 24th International Networking for Healthcare Education Conference, University of Cambridge, UK. 2013.

27. Al Jarrah IAT. Associate nursing students' perceptions toward nursing profession in Jordan. European Scientific Journal. 2013;9:147-66.

28. Ibrahim AF, Akel DT, Alzghoul HWM. Image of nursing profession as perceived by Egyptian and Jordanian undergraduate male nursing students: A comparative study. Journal of Education Practice. 2015;6(14):24-36.

29. Lu KY, Chiou SL. Professional commitment of nursing students. J Nurs Res. 1998;6(2):109-20.

30. Blomstrom S. Identifying teaching effectiveness: Using student skill surveys, speech evaluations, and quiz scores to inform instruction. Communication Theater Association of Minnesota Journal. 2010;37(1):116-32.

31. Cain MK, Zhang Z, Yuan K-H. Univariate and multivariate skewness and kurtosis for measuring nonnormality: Prevalence, influence and estimation. Behav Res Methods. 2017;49(5):1716-35.

32. Hair JF, Thomas G, Hult M, Ringle CM, Sarstedt M. A primer on partial least squares structural equation modeling (PLS-SEM). 2nd ed. Thousand Oaks: Sage; 2017.

33. Ringle CM, Wende S, Becker J-M. SmartPLS 3. Boenningstedt: SmartPLS GmbH; 2015.

34. Hair JF, Sarstedt M, Ringle CM, Gudergan SP. Advanced issues in partial least squares structural equation modeling. Thousand Oaks: Sage; 2018.

35. Henseler J, Hubona G, Ray PA. Using PLS path modeling in new technology research: Updated guidelines. Industrial Management Data Systems. 2016;116(1):2-20.

36. Fornell C, Larcker DF. Structural equation models with unobservable variables and measurement error: Algebra and statistics. Los Angeles: Sage; 1981.

37. McCance TV, McKenna HP, Boore JR. Caring. Theoretical perspectives of relevance to nursing. J Adv Nurs. 1999;30(6):1388-95.

\section{Tables}

Table 1 Factor loading, $C R$, and AVE for the measurement variables $(N=108)$ 


\begin{tabular}{|c|c|c|c|c|c|c|c|c|c|}
\hline \multirow[t]{2}{*}{ Construct measure } & \multicolumn{3}{|c|}{ Total sample $(N=108)$} & \multicolumn{3}{|c|}{ Female $(n=80)$} & \multicolumn{3}{|c|}{ Male $(n=28)$} \\
\hline & Loading & $\mathrm{CR}$ & AVE & Loading & $\mathrm{CR}$ & AVE & Loading & $\mathrm{CR}$ & AVE \\
\hline Self-reflection and insight & & 0.94 & 0.83 & & 0.87 & 0.69 & & 0.92 & 0.80 \\
\hline Engage & 0.91 & & & 0.89 & & & 0.96 & & \\
\hline Need & 0.73 & & & 0.70 & & & 0.82 & & \\
\hline Insight & 0.90 & & & 0.89 & & & 0.91 & & \\
\hline Learning effectiveness & & 0.89 & 0.72 & & 0.94 & 0.83 & & 0.95 & 0.86 \\
\hline Self-motivation & 0.93 & & & 0.94 & & & 0.87 & & \\
\hline Self-regulation & 0.93 & & & 0.92 & & & 0.97 & & \\
\hline Self-efficacy & 0.89 & & & 0.87 & & & 0.94 & & \\
\hline Nursing competence & & 0.94 & 0.79 & & 0.93 & 0.78 & & 0.95 & 0.84 \\
\hline General aptitude & 0.81 & & & 0.81 & & & 0.84 & & \\
\hline Ethically oriented practice & 0.91 & & & 0.90 & & & 0.94 & & \\
\hline Nursing care in a team & 0.93 & & & 0.93 & & & 0.93 & & \\
\hline Professional development & 0.91 & & & 0.89 & & & 0.95 & & \\
\hline Caring behavior & & 0.97 & 0.91 & & 0.97 & 0.91 & & 0.98 & 0.95 \\
\hline Sense of security & 0.95 & & & 0.94 & & & 0.96 & & \\
\hline Comfort & 0.96 & & & 0.95 & & & 0.98 & & \\
\hline Accessibility & 0.96 & & & 0.96 & & & 0.98 & & \\
\hline Professional socialization & & 0.85 & 0.65 & & 0.84 & 0.63 & & 0.88 & 0.70 \\
\hline Team skill & 0.74 & & & 0.66 & & & 0.89 & & \\
\hline Nursing image & 0.85 & & & 0.88 & & & 0.80 & & \\
\hline Professional commitment & 0.82 & & & 0.83 & & & 0.82 & & \\
\hline
\end{tabular}

Note. $\mathrm{CR}=$ composite reliability, $\mathrm{AVE}=$ average variance .

Table 2. Discriminant validity/Fornell-Larcker criterion $(N=108)$ 


\begin{tabular}{|c|c|c|c|c|c|c|c|c|c|c|c|c|c|c|c|}
\hline \multirow[b]{2}{*}{$\begin{array}{l}\text { Construct } \\
\text { measure }\end{array}$} & \multicolumn{5}{|c|}{ Total sample $(N=108)$} & \multicolumn{5}{|c|}{ Female $(n=80)$} & \multicolumn{5}{|c|}{ Male $(n=28)$} \\
\hline & 1 & 2 & 3 & 4 & 5 & 1 & 2 & 3 & 4 & 5 & 1 & 2 & 3 & 4 & 5 \\
\hline $\begin{array}{l}\text { 1. Learning } \\
\text { effectiveness }\end{array}$ & 0.91 & & & & & 0.91 & & & & & 0.93 & & & & \\
\hline $\begin{array}{l}\text { 2. Caring } \\
\text { behavior }\end{array}$ & 0.47 & 0.96 & & & & 0.50 & 0.95 & & & & 0.37 & 0.97 & & & \\
\hline $\begin{array}{l}\text { 3. Self- } \\
\text { reflection }\end{array}$ & 0.41 & 0.35 & 0.85 & & & 0.46 & 0.36 & 0.83 & & & 0.33 & 0.37 & 0.90 & & \\
\hline $\begin{array}{l}\text { 4. Nursing } \\
\text { competence }\end{array}$ & 0.49 & 0.74 & 0.51 & 0.89 & & 0.52 & 0.70 & 0.52 & 0.88 & & 0.42 & 0.85 & 0.50 & 0.92 & \\
\hline $\begin{array}{l}5 . \\
\text { Professional } \\
\text { socialization }\end{array}$ & 0.59 & 0.56 & 0.48 & 0.61 & 0.81 & 0.52 & 0.52 & 0.42 & 0.57 & 0.80 & 0.78 & 0.69 & 0.63 & 0.70 & 0.84 \\
\hline
\end{tabular}

Note. Diagonal elements (bold) are the square root of the average variance extracted for each construct; off-diagonal elements are inter-construct correlations.

Table 3. Metric invariance assessment permutation algorithm of two groups $(N=108)$ 


\begin{tabular}{|c|c|c|c|}
\hline \multirow[t]{2}{*}{ Construct/indicator } & \multicolumn{3}{|l|}{ Permutation test } \\
\hline & Mean difference ( female - male) & $95 \%$ confidence interval & $p$-value (all ns) \\
\hline \multicolumn{4}{|l|}{ Self-reflection and insight } \\
\hline Engage & 0.003 & $-0.073 ; 0.102$ & 0.110 \\
\hline Insight & 0.008 & $-0.217 ; 0.338$ & 0.358 \\
\hline Need & 0.004 & $-0.089 ; 0.128$ & 0.712 \\
\hline \multicolumn{4}{|l|}{ Nursing competence } \\
\hline General aptitude & 0.001 & $-0.124 ; 0.161$ & 0.670 \\
\hline Ethically oriented practice & -0.001 & $-0.069 ; 0.084$ & 0.298 \\
\hline Nursing care in a team & 0.001 & $-0.057 ; 0.086$ & 0.889 \\
\hline Professional development & 0.001 & $-0.084 ; 0.125$ & 0.303 \\
\hline \multicolumn{4}{|l|}{ Caring behavior } \\
\hline Sense of security & 0.000 & $-0.031 ; 0.045$ & 0.440 \\
\hline Comfort & 0.003 & $-0.051 ; 0.093$ & 0.704 \\
\hline Accessibility & 0.002 & $-0.043 ; 0.078$ & 0.346 \\
\hline \multicolumn{4}{|l|}{ Learning effectiveness } \\
\hline Self-motivation & 0.003 & $-0.071 ; 0.128$ & 0.130 \\
\hline Self-regulation & 0.001 & $-0.096 ; 0.153$ & 0.286 \\
\hline Self-efficacy & 0.000 & $-0.060 ; 0.083$ & 0.156 \\
\hline \multicolumn{4}{|l|}{ Professional socialization } \\
\hline Team skill & 0.008 & $-0.129 ; 0.203$ & 0.290 \\
\hline Nursing image & 0.025 & $-0.274 ; 0.690$ & 0.315 \\
\hline Professional commitment & 0.004 & $-0.153 ; 0.250$ & 0.946 \\
\hline
\end{tabular}

Table 4. The measurement invariance of composite model (MICOM) tests $(N=108)$ 


\begin{tabular}{|c|c|c|c|c|}
\hline $\begin{array}{l}\text { Construct } \\
\text { (composite) }\end{array}$ & Correlation $c$ & $\begin{array}{l}5 \% \text { quantile of the empirical } \\
\text { distribution of } \mathrm{C}_{\mathrm{u}}\end{array}$ & $\begin{array}{l}p- \\
\text { value }\end{array}$ & $\begin{array}{l}\text { Compositional invariance } \\
\text { established }\end{array}$ \\
\hline Caring behavior & 1.000 & 1.000 & 0.192 & Yes \\
\hline $\begin{array}{l}\text { Nursing } \\
\text { competence }\end{array}$ & 1.000 & 0.999 & 0.740 & Yes \\
\hline $\begin{array}{l}\text { Professional } \\
\text { socialization }\end{array}$ & 0.991 & 0.918 & 0.631 & Yes \\
\hline Self-reflection & 0.998 & 0.970 & 0.626 & Yes \\
\hline $\begin{array}{l}\text { Learning } \\
\text { effectiveness }\end{array}$ & 0.998 & 0.994 & 0.326 & Yes \\
\hline $\begin{array}{l}\text { Construct } \\
\text { (composite) }\end{array}$ & $\begin{array}{l}\text { Mean difference } \\
\text { (female - male) }\end{array}$ & $95 \%$ confidence interval & $\begin{array}{l}p- \\
\text { value }\end{array}$ & Equal mean values \\
\hline Caring behavior & -0.065 & $-0.424 ; 0.401$ & 0.767 & Yes \\
\hline $\begin{array}{l}\text { Nursing } \\
\text { competence }\end{array}$ & -0.175 & $-0.412 ; 0.414$ & 0.440 & Yes \\
\hline $\begin{array}{l}\text { Professional } \\
\text { socialization }\end{array}$ & -0.264 & $-0.436 ; 0.442$ & 0.236 & Yes \\
\hline Self-reflection & -0.284 & $-0.462 ; 0.444$ & 0.202 & Yes \\
\hline $\begin{array}{l}\text { Learning } \\
\text { effectiveness }\end{array}$ & -0.118 & $-0.437 ; 0.416$ & 0.616 & Yes \\
\hline $\begin{array}{l}\text { Construct } \\
\text { (composite) }\end{array}$ & $\begin{array}{l}\text { Variance mean difference } \\
\text { (female - male) }\end{array}$ & $95 \%$ confidence interval & $\begin{array}{l}p- \\
\text { value }\end{array}$ & Equal variances \\
\hline Caring behavior & 0.015 & $-0.620 ; 0.717$ & 0.959 & Yes \\
\hline $\begin{array}{l}\text { Nursing } \\
\text { competence }\end{array}$ & -0.339 & $-0.543 ; 0.651$ & 0.295 & Yes \\
\hline $\begin{array}{l}\text { Professional } \\
\text { socialization }\end{array}$ & -0.113 & $-0.504 ; 0.668$ & 0.693 & Yes \\
\hline Self-reflection & -0.494 & $-0.530 ; 0.584$ & 0.093 & Yes \\
\hline $\begin{array}{l}\text { Learning } \\
\text { effectiveness }\end{array}$ & 0.047 & $-0.352 ; 0.469$ & 0.796 & Yes \\
\hline
\end{tabular}

Table 5. Two-group comparison test results/permutation test 


\begin{tabular}{|c|c|c|c|c|}
\hline Full model & $\begin{array}{l}\text { Path coefficient- } \\
\text { Original }\end{array}$ & $\begin{array}{l}\text { Path coefficient- } \\
\text { Mean }\end{array}$ & $S D$ & $t$-value \\
\hline Caring behavior $->$ Nursing competence & 0.64 & 0.64 & 0.065 & $9.891^{\star \star *}$ \\
\hline Caring behavior $->$ Self reflection & 0.21 & 0.21 & 0.117 & 1.748 \\
\hline $\begin{array}{l}\text { Nursing competence }->\text { Professional } \\
\text { socialization }\end{array}$ & 0.61 & 0.62 & 0.068 & $8.968^{\star \star \star}$ \\
\hline Self-reflection -> Nursing competence & 0.29 & 0.28 & 0.081 & $3.543^{\star * *}$ \\
\hline Learning effectiveness -> Caring behavior & 0.47 & 0.47 & 0.082 & $5.727 * \star \star$ \\
\hline Learning effectiveness -> Self-reflection & 0.32 & 0.32 & 0.095 & $3.318 * \star$ \\
\hline Female & $\begin{array}{l}\text { Path coefficient- } \\
\text { Original }\end{array}$ & $\begin{array}{l}\text { Path coefficient- } \\
\text { Mean }\end{array}$ & $S D$ & $t$-value \\
\hline Caring behavior $->$ Nursing competence & 0.59 & 0.60 & 0.077 & 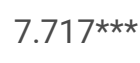 \\
\hline Caring behavior -> Self reflection & 0.17 & 0.19 & 0.149 & 1.138 \\
\hline $\begin{array}{l}\text { Nursing competence -> Professional } \\
\text { socialization }\end{array}$ & 0.57 & 0.59 & 0.080 & $7.133^{\star \star \star}$ \\
\hline Self-reflection $->$ Nursing competence & 0.31 & 0.30 & 0.105 & $2.942^{\star \star}$ \\
\hline Learning effectiveness -> Caring behavior & 0.50 & 0.51 & 0.094 & $5.337 * \star \star$ \\
\hline Learning effectiveness -> Self-reflection & 0.37 & 0.36 & 0.128 & $2.886^{\star \star}$ \\
\hline Male & $\begin{array}{l}\text { Path coefficient- } \\
\text { Original }\end{array}$ & $\begin{array}{l}\text { Path coefficient- } \\
\text { Mean }\end{array}$ & $S D$ & $t$-value \\
\hline Caring behavior $->$ Nursing competence & 0.77 & 0.74 & 0.103 & $7.458^{* \star *}$ \\
\hline Caring behavior $->$ Self reflection & 0.29 & 0.30 & 0.218 & 1.316 \\
\hline $\begin{array}{l}\text { Nursing competence -> Professional } \\
\text { socialization }\end{array}$ & 0.70 & 0.72 & 0.098 & $7.193^{\star \star *}$ \\
\hline Self-reflection $->$ Nursing competence & 0.22 & 0.23 & 0.108 & $2.004^{\star}$ \\
\hline Learning effectiveness $->$ Caring behavior & 0.37 & 0.39 & 0.179 & $2.080^{*}$ \\
\hline Learning effectiveness -> Self-reflection & 0.22 & 0.24 & 0.183 & 1.222 \\
\hline Permutation test & $\begin{array}{l}\text { Path coefficient- } \\
\text { Female }\end{array}$ & $\begin{array}{l}\text { Path coefficient- } \\
\text { Male }\end{array}$ & $\begin{array}{l}\text { Difference (female - } \\
\text { male) }\end{array}$ & $t$-value \\
\hline Caring behavior $->$ Nursing competence & 0.59 & 0.77 & -0.002 & 0.277 \\
\hline Caring behavior $->$ Self-reflection & 0.17 & 0.29 & -0.028 & 0.716 \\
\hline $\begin{array}{l}\text { Nursing competence -> Professional } \\
\text { socialization }\end{array}$ & 0.57 & 0.70 & -0.037 & 0.452 \\
\hline Self-reflection -> Nursing competence & 0.31 & 0.22 & 0.008 & 0.665 \\
\hline Learning effectiveness -> Caring behavior & 0.50 & 0.37 & -0.019 & 0.537 \\
\hline Learning effectiveness -> Self-reflection & 0.37 & 0.22 & 0.005 & 0.533 \\
\hline
\end{tabular}

${ }^{\star} p \leq 0.05,{ }^{\star \star} p \leq 0.01,{ }^{* \star *} p \leq 0.001$

\section{Figures}




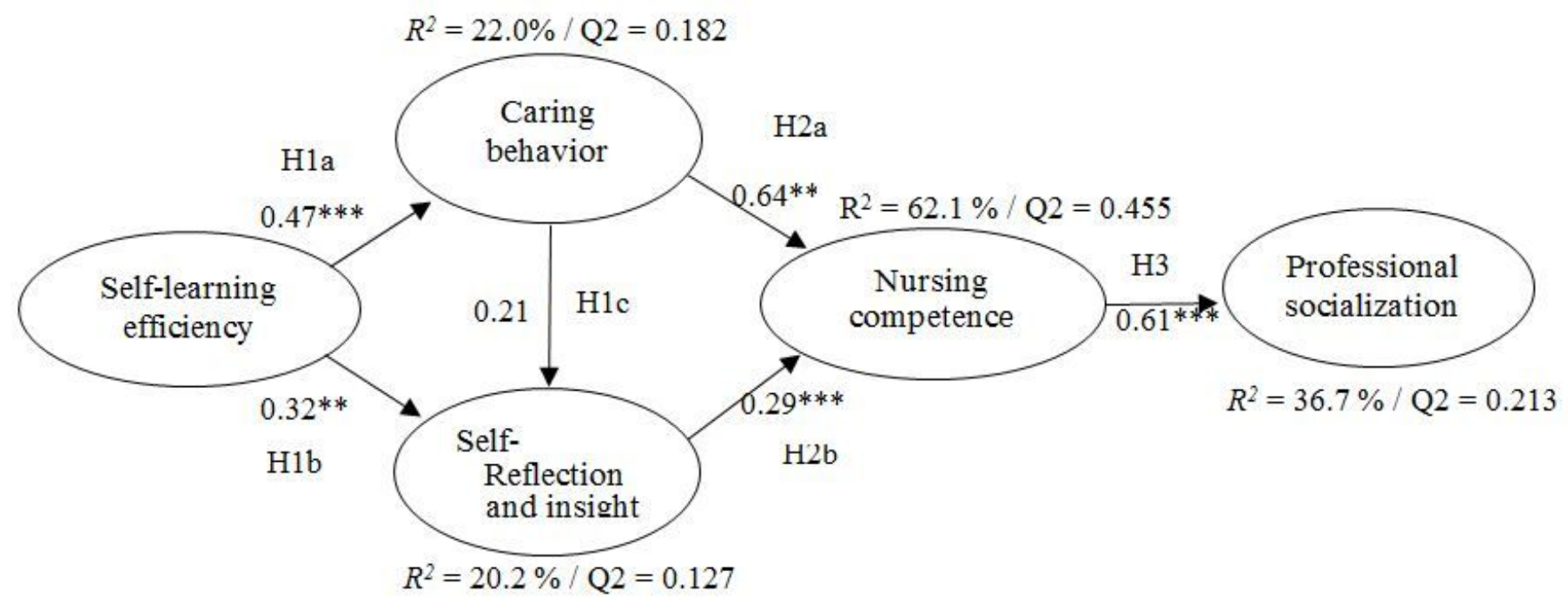

Figure 1

Hypotheses and results of conceptual model.

\section{Supplementary Files}

This is a list of supplementary files associated with this preprint. Click to download.

- STROBEchecklistcrosssectional.docx 